Article

\title{
Sustainable Construction: Improving Productivity through Lean Construction
}

\author{
Tamar Awad * ${ }^{\mathbb{D}}$, Jesús Guardiola and David Fraíz *
}

Citation: Awad, T.; Guardiola, J.; Fraíz, D. Sustainable Construction: Improving Productivity through Lean Construction. Sustainability 2021, 13, 13877. https://doi.org/10.3390/ su132413877

Academic Editors:

Roberto Alonso González Lezcano and Marc A. Rosen

Received: 26 October 2021

Accepted: 8 December 2021

Published: 15 December 2021

Publisher's Note: MDPI stays neutral with regard to jurisdictional claims in published maps and institutional affiliations.

Copyright: (c) 2021 by the authors. Licensee MDPI, Basel, Switzerland. This article is an open access article distributed under the terms and conditions of the Creative Commons Attribution (CC BY) license (https:// creativecommons.org/licenses/by/ $4.0 /)$.
Department of Mechanical Engineering, Technical School of Engineering at ICAI, Comillas University, 28015 Madrid, Spain; jguardiola@comillas.edu

* Correspondence: tawad@comillas.edu (T.A.); dfraiz@comillas.edu (D.F.)

\begin{abstract}
The objective of this article is to improve building productivity, evolving from traditional construction to industrial construction. The methodology used here consists of analysing the use of materials, the construction design, the design of the spatial distribution programme, the use of auxiliary means and resources and the application of lean tools in construction. The results achieved here include a complete building system that integrates the design, project and execution, wherein the construction process is improved and inconsistencies in the final project are reduced. With the application of an industrial manufacturing methodology, the productivity in construction is improved, reducing costs, materials, execution times and waste. These productivity improvements result in construction being more sustainable. As a conclusion of the previous analysis, the elements that must be integrated into a complete building project and the need to incorporate industrial manufacturing into construction processes in order to achieve sustainable architecture are established.
\end{abstract}

Keywords: lean manufacturing; modular construction; sustainability architecture; efficient buildings; sustainability; lean construction

\section{Introduction}

The intention of this article is to study construction in order to propose a sustainable method in which it can be carried out. One possible way to achieve this is through the application of lean manufacturing in construction processes.

The lean concept [1] was born in the 1930s through the observation of processes in Toyota factories [2] and, since then, it has typically been applied in productive or industrial processes through the use of different techniques and tools, such as 5s, SMEN, QFD, TPM, Kamban and Pocayoke, etc., achieving adjusted production. With sustained applications over time, the continuous improvement and optimisation of different productive processes are achieved.

For this process, the lean methodology seeks the reduction of "waste," commonly in seven categories: Overproduction, waiting time, transport, excess procedures, inventory, movements, defects and the non-contribution of the operator in obtaining ideas that can improve processes.

As can be seen, this waste produced in the manufacturing industry is easily extrapolated to the building sector, as the construction process is considered to be an industrial or productive process [3].

Combining the use of the lean methodology in construction [4] and BIM (Building Information Modelling) [5] for integrated building management would be the best way to improve sustainability in construction, thereby achieving certain SDGs goals, such as 9, 11 and $12[6]$.

The production process in construction should be understood as an integrated process as are other industrial activities. However, at present, it is very fragmented, categorised as independent fields such as design, focused on the speciality of architecture; the execution 
of the project, split between architects and engineers; and construction, carried out by independent companies separate from the fields of action of those previous, where architects and engineers are also present.

When considering any other process and development in the industrial field, the activities, tasks, and work are coordinated, managed, and directed in a very different way to building processes.

Construction, in order to be included in an industrial dynamic, should combine the following stages: Design, devising the space, the project, the transfer to production, and finally, the construction of the work, as well as the post-sale follow-up.

An analysis of today's buildings has many characteristic aspects that are different from typical industrial production, where all production activities are usually controlled by the same entity or company and fall under the same methodology, standards, regulations, and common performance objectives.

Lean techniques can be applied to all steps of the construction process, which encompass lean project definition, lean design, lean supply, lean assembly, and others [7]. The focus is on how a lean design and lean assembly can be combined to contribute to a sustainable production process.

The production of buildings is carried out in three phases: Design, engineering, and assembly [8].

In development, there are the following three stages:

- Design: Focusing on the treatment of the habitat and functional conditions of the building.

- Engineering: Referring to the preparation of the design for construction.

- Assembly: On-site construction of the building.

The results of this development are oriented towards obvious economic advantages, such as a cost reduction, which is socially necessary. The deadline, which is an aspect directly linked to the cost, will also be addressed more than the economic aspect.

Other advantages of the reorientation of building to an industrial environment include quality assurance, sustainability [9] and digitalisation.

Unlike manufacturing, construction is a project-based production process. Lean construction [10] is concerned with the integral pursuit of simultaneous and continuous improvements in all dimensions of the built and natural environment: Design, construction, commissioning, maintenance, recovery, and recycling.

\section{Materials and Methods}

The methodology is based on an analysis of the elements involved in the design and construction process. Through the use of lean tools, productivity is improved, which results in construction being sustainable. The following five aspects are developed below: An analysis of the current situation, the discourse of the method, an analysis of UNEEN 15643-3-2012, the definition of the programme and the meaning of construction as engineering through a price decomposition analysis.

Firstly, an analysis is conducted of the current state of the art [2], the traditional building processes and the challenges of new buildings related to the industrialisation available. We also analysed the advances achieved and the possible solutions for the application in the construction industry.

\subsection{Analysis of the Current Situation: Industrial versus Traditional Construction}

Since the end of the 1980s, the lean philosophy has been adopted in the construction sector with a focus on efficiency, mainly motivated by economic competition [11].

In terms of industrialisation, there are differences between products and technology. Products refer to construction components available on the market, and technologies to the methodologies for on-site assembly. 


\subsubsection{Products and Technologies}

Nowadays, sufficient materials, products and systems are available to develop a more advanced building technology [12] than traditional building systems of the past.

Products:

- In situ: Made on-site, semi-finished, they require time to dry or set, they also need auxiliary means, formwork, falsework...

- Workshop: custom-built off-site, available unassembled and ready to install on-site.

- Factory: Standardised, ready to be assembled on-site, adjusts to measurements easily. Technologies:

- Craftsmanship: Labour-intensive on-site assembly, bonding with binders and adhesives.

- Industrial: Labour-simplified assembly, with standards or instructions, dry assembly by screwing, adjusting, skilled and specialised labour.

Figure 1 is a study of the combination possibilities between the origin of materials and the technology used.

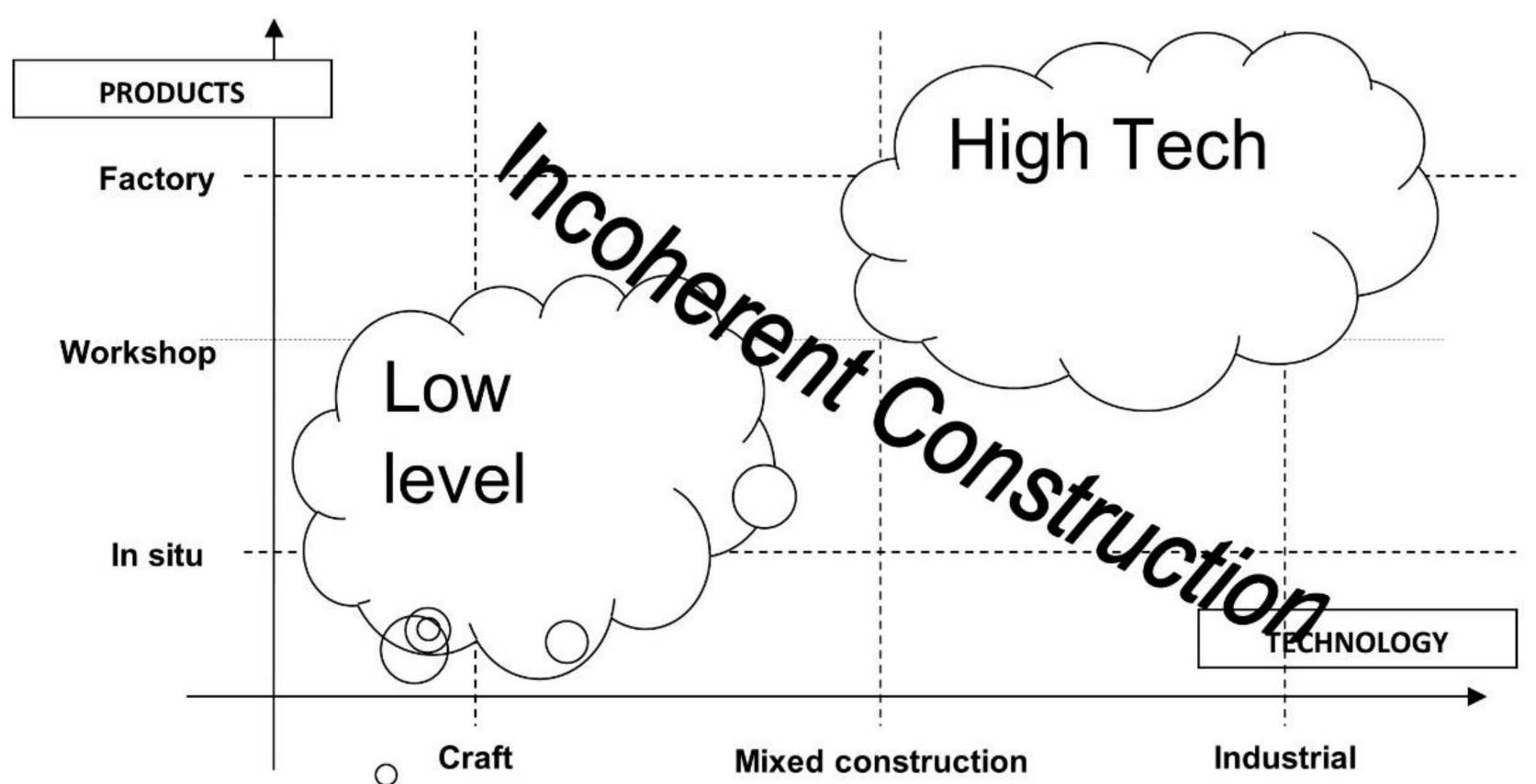

Figure 1. Products and technology (own source).

Incoherent construction happens when technology and product categories that do not correspond are mixed. Outside the "cloud" areas, advanced industrial design technological products are combined with traditional, archaic construction.

\subsubsection{Technology and Design}

This is an analysis of building systems and technologies and their connection to the elements of programme design and space distribution.

Sometimes, architecture that is intended to use advanced construction systems is paradoxically executed with handcrafted construction. This results in incoherence between design and construction.

Two construction systems can be distinguished as shown in Figure 2. 


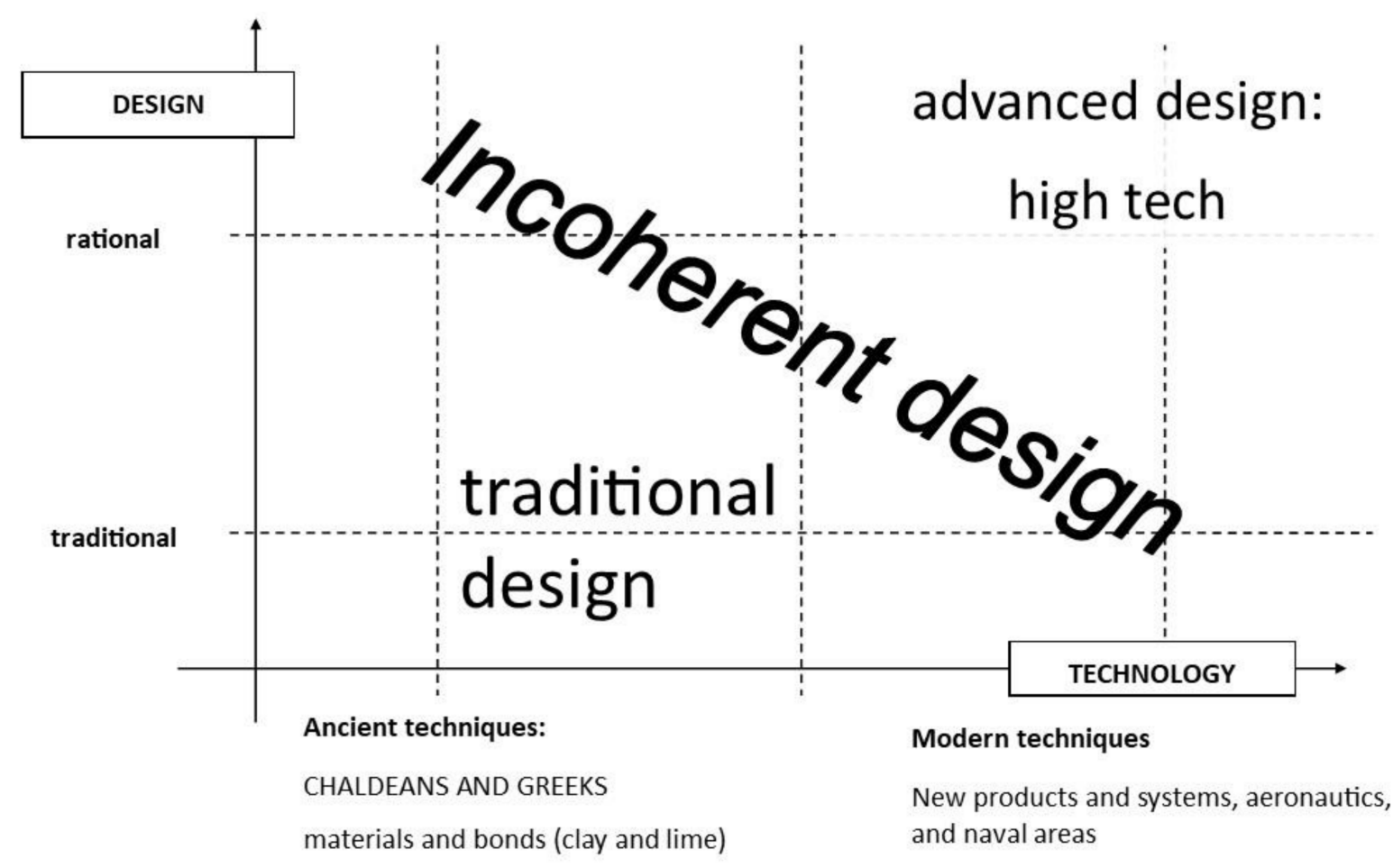

Figure 2. Design and technology (own source).

System based on ancient techniques and materials: from archaic eras, based on earthy materials and hydraulic joining methods, which combine water with binders that set over time.

Modern systems based on external technologies: Aeronautical, naval [13] and others, which provide lighter materials, composites of elements with combined properties, according to more optimized requirements, as well as more rationalised execution methods.

There are four possible outcomes distinguished by the design of the habitat and the construction technology provided.

- Rational and contemporary design combined with advanced technology: High tech [14].

- Conservative and outdated design with archaic construction: Traditional design.

- Rational design using traditional construction technology.

- Conservative design using advanced technology.

The first two possibilities are coherent and parallel between the design criteria and the technology chosen for their execution; however, the latter two produce an incoherent result.

\subsection{Stages of the Construction Project}

Once the current situation has been analysed, reviewing the building project [6] can lead to an improvement in the construction process, resulting in a better level of quality, lower cost, and shorter execution time.

The complete cycle is reviewed-design, project, and assembly-in order to obtain a better performance in terms of cost and construction time. This process review, which is carried out within the lean construction methodology [15], seeks the optimisation of each process of components, resources and materials.

According to Koskela, there are two main processes in a construction project:

- Design process: this is a step-by-step refinement of specifications where vague needs and wishes are transformed into requirements, and after a variable number of steps, into detailed designs.

- Construction process: Composed of two different types of flows; material process and construction equipment work processes. 
Processes can be characterised by their cost, duration, and value to the customer [16].

A lean analysis in construction must be based on the order of stages established in construction projects, as set out in the UNE-EN 15643-3-2012 standard: Terminology of Engineering Services in Buildings, Infrastructures, and Industrial Installations.

To analyse the complete construction process, from the design to the material execution, the description of the UNE-EN 15643-3-2012 standard is used.

UNE-EN 15643-3-2012 is a reference to sustainability in construction.

From the following chart, Figure 3, we have chosen the following stages of development of a construction project. Those that will best fit the above-mentioned arguments of "design" and "material execution" are the following:

0 . Initiative:

0.1. Market Study

0.2. Business Case

1. Start:

1.1. Project Start

1.2. Viability Study

1.3. Project Definition

2. Design:

2.1. Conceptual Design

2.2. Preliminary Design

2.3. Technical Design

2.4. Detail Design

Among the four design stages listed in the UNE-EN 15643-3-2012, the conceptual design and the preliminary design belong to the architecture project group, while technical design and detail design would be in the engineering execution group.

On an architectural level, in the project development phase, we will analyse the architectural design manners of the habitat in order to find lines of improvement in the organisation of the programme.

For the second group—engineering-oriented to the material execution of the project, the economic configuration is studied, with price base and deadlines.

The main variables to be considered in costs are:

- Materials

- Manpower: M.P.

- Auxiliary resources: A.R.

Materials are the products that enter the construction site for assembly or joining. Manpower is the human resources necessary to carry out the work. The auxiliary resources are the means to facilitate such work, tools, and machines.

By analysing the architectural elements, the way to optimise cost efficiency is studied, from the revised design aimed at improving the productivity of execution to the cost components and construction times to be reduced, depending on the construction process itself.

The next subsection is an analysis of each of these two groups, framed in the "architecture" and "engineering" of the construction processes, including the stages set out for each of them, the particular developments of the project, seeking options for cuts and elimination of superfluous elements, typical of lean methodology in construction.

\subsection{Design: Definition of the Programme}

The industrial engineer [17], who designs cars, railways, aeroplanes, and ships, surpasses the construction engineer by using mechanically processed materials and methods for rational production. The problem has to be approached from three interdependent factors: economy, technology and method. 


\begin{tabular}{|c|c|c|c|c|c|c|}
\hline \multicolumn{2}{|c|}{$\begin{array}{l}\text { EN 15643-3- } \\
2012\end{array}$} & STAGES & & SUBSTAGES & \multirow{8}{*}{ 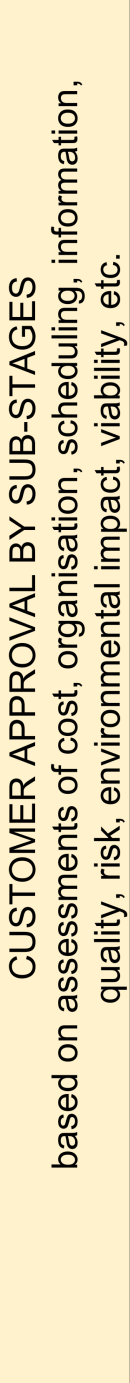 } & \multirow{8}{*}{ 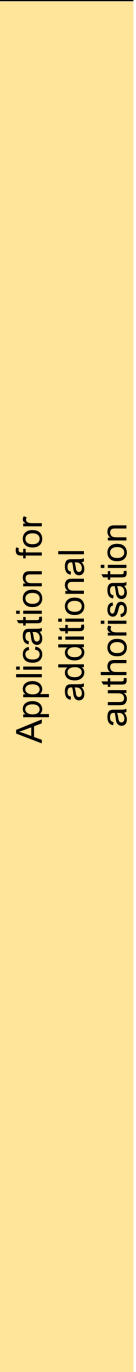 } \\
\hline \multirow{5}{*}{ 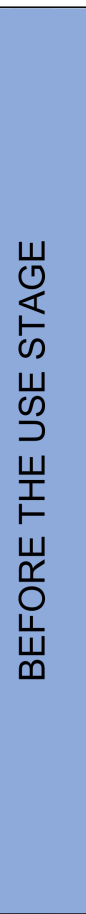 } & \multirow{4}{*}{ 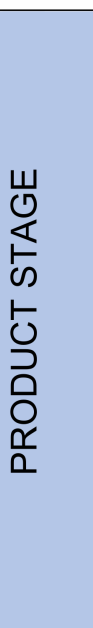 } & 0. INITIATIVE & $\begin{array}{l}0.1 \\
0.2\end{array}$ & $\begin{array}{l}\text { Market study } \\
\text { Business case }\end{array}$ & & \\
\hline & & 1. START & $\begin{array}{l}1.1 \\
1.2 \\
1.3\end{array}$ & $\begin{array}{l}\text { Project start } \\
\text { Viability study } \\
\text { Project definition }\end{array}$ & & \\
\hline & & 2. DESIGN & $\begin{array}{l}2.1 \\
2.2\end{array}$ & $\begin{array}{l}\text { Conceptual } \\
\text { design } \\
\text { Preliminary design } \\
\text { and developed } \\
\text { design } \\
\text { Technical design } \\
\text { Detail design }\end{array}$ & & \\
\hline & & 3. PROCUREMENT & $\begin{array}{l}3.1 \\
3.2\end{array}$ & $\begin{array}{l}\text { Procurement } \\
\text { Construction } \\
\text { contract }\end{array}$ & & \\
\hline & 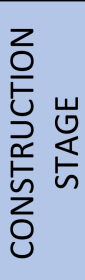 & 4. CONSTRUCTION & $\begin{array}{l}4.1 \\
4.2 \\
4.3 \\
4.4 \\
4.5\end{array}$ & $\begin{array}{l}\text { Pre-construction } \\
\text { Construction } \\
\text { Implementation } \\
\text { Delivery } \\
\text { Statutory approval }\end{array}$ & & \\
\hline \multicolumn{2}{|c|}{ 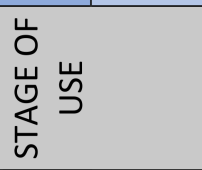 } & 5. USE & $\begin{array}{l}5.1 \\
5.2\end{array}$ & $\begin{array}{l}\text { Operation } \\
\text { Maintenance }\end{array}$ & & \\
\hline \multicolumn{2}{|c|}{ 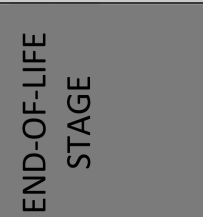 } & 6. END OF LIFE & & $\begin{array}{l}\text { Refurbishment } \\
\text { Dismantling }\end{array}$ & & \\
\hline
\end{tabular}

Figure 3. Based on UNE-EN 15643-3-2012: sustainability in construction: sustainability assessment in buildings.

The economic factor consists of analysing cost reduction, the technological one of providing the materials, products, and components, all based on mass production means, and the method, which deals with the rational composition of the living space and its design, on the other hand.

From the historical analysis of habitat needs, two common strategies can be observed: the revision of the way of living, its needs or corresponding consumption of space and the search for technologies that facilitate its execution, with the aim of economising costs and economic effort.

Thus, from new solutions and revised approaches to the habitat scheme, the aim is to achieve a new rational industrialised building.

Before moving on to industrial production in construction, the requirements and use of the spaces have to be clear.

The design of space is looking for housing with rational use. As a result of this, there are habits that have to be revised, rationalising the organisation of living space.

A building system that combines design and execution will facilitate the typical construction processes, based on industrial construction engineering, transferring methodologies that improve the productivity of construction on-site, and that will optimize lean construction.

This section begins to focus the analysis on the design of the "product" itself, which is the habitat. 


\subsubsection{Functional Analysis}

Facing a new form of construction affects both the specific execution process and the design of the space.

It is necessary to delve into the design from the beginning, analysing the habitat or way of living, its relations and internal functions and its needs and uses; in short, its functional programme.

The in-depth study of this section is enormously complex as it is an extensive field of analysis, in all its cultural, sociological, and psychological components; many authors, analysts and architecture professionals have been working for some time on the exclusive subject of housing, including its political implications since the last century, with enormously committed positions.

In this sense, the CIAM congresses, Le Corbusier's Athens Charter [18] and all that follow are both in favour and broad critical positions: Team X and Hadraken's diagrammatic methodology [19], Japanese Metabolists [20], and Archigram [21]. Up to the present day, this is a debate that is still unfinished.

The issue of housing has long been a problem of difficult satisfaction for society.

At the beginning of the 20th century, the social and economic panorama began to change, with the studies of the Industrial City by Tony Garnier [22], in which new approaches to an integrated habitat were presented.

From the early years of Russian constructivism, through the successive trends of modern architecture, solutions of housing units have been collected (Le Corbusier), in the approaches of minimal housing, on arguments of hygiene and health or in the revision of a new way of life, open to nature and today's society, for example, Los Angeles architecture with case study houses.

Likewise, even designs have been revised to facilitate a better and more rational construction: the five points of Le Corbusier, Bauhaus school [23], Prouvé, even in Spain, the contribution of Rafael de la Hoz [24] stands out, looking for solutions in architectural elements.

On the other hand, pioneering engineers, using new materials such as steel, concrete, plastics, and laminated wood, in line with the industrialisation of building, such as E.L. Ransome $[25,26]$ in the use of prefabricated concrete parts in the USA or Freyssinet in France, with the evolution of pre-stressed concrete [27], provide applications in civil and industrial fields.

Governments, city councils and schools of design and architecture universities have always been gradually getting involved, looking for the solution to the population's need for housing. This began with the pressing problems that arose after the Second World War, where Europe lost an enormous number of buildings and housing and looked for quick and emergency solutions, from which the first applications of mass prefabrication [28] emerged but did not turn out to be the desired solution.

\subsubsection{Rational Design: The Architectural Project}

This section analyses the minimum elements necessary for the habitat.

There is no justification for the fact that every house in a suburban neighbourhood has a different typology: different floor plans, facades and building materials. Throughout Europe, the old farmhouse, and the townhouse of the average citizen in the 18th century show a similar layout.

Except for the typologies revised during the modern movement, in search of the minimum house solution, the way of living is still traditional, falsely conditioned by the construction of load-bearing walls, where rooms are enclosed between walls and elongated corridors.

Housing should be designed according to the requirements of the family unit but tending to standardise the common parts, eliminating unnecessary uses and spaces and generalising related spaces. 
The optimisation of the habitat focuses on the strategy of reducing architectural components through function and use, using architectural elements that configure spaces according to their use.

According to A. Moles, the necessary minimum elements of a space configuration can be determined as [29]:

A. The sphere of the "immediate gesture": It is made up of the furniture close to each function.

B. The "room," the minimum determined space, configured by each function in a space, delimited by partitions.

C. The "flat," the composition of complete functions of the habitat, configuring the hierarchy of complete functions of a habitat.

In this strategy of minimums can be referenced the design modes for a revised habitat result, with the saving of architectural resources, which ultimately saves costs, preserving user value.

As an example, we can propose solutions, taken from the courses at the Madrid School of Architecture, taught by A. Fernández Alba in the 1970s [30].

In these solutions, the concepts of minimal conceptual strategies applied to the proposed spaces are tested (Figure 4).

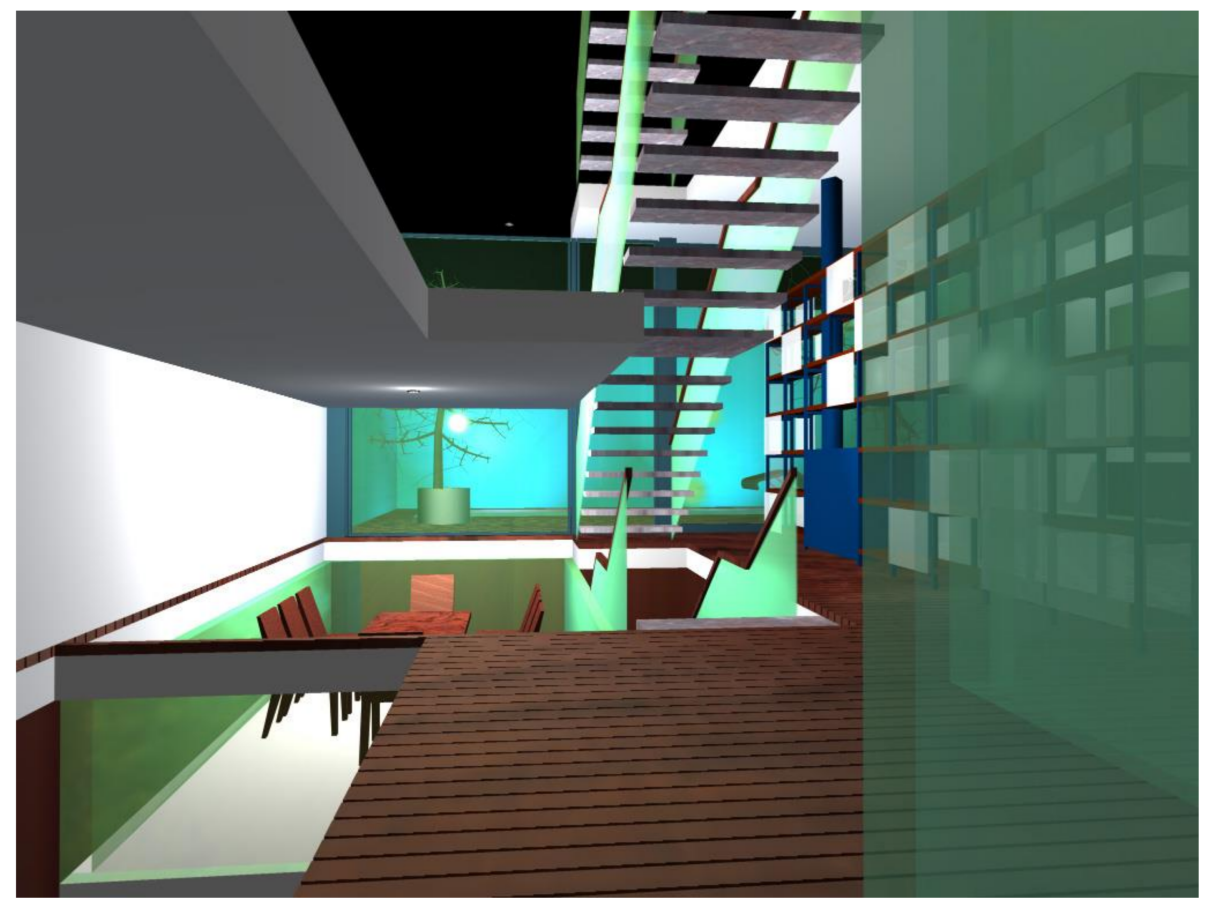

Figure 4. Interior perspective: rehearsal of the organisation of living space: J. Guardiola.

Elements of Design

A more controlled design of the habitat conditions, programme, space and uses favours the rationalisation of the execution on the elements of the construction: Walls, installations or façades.

The basic functions can be pointed out, which will help rethink less traditional housing solutions and involve more current approaches among the needs of the habitat.

Functionality

The design premises, at afunctional level, which present the problem of building organisation are set out under the following principles:

- Privacy and community: the private and the common

- Functional spaces 
- Sociological changes

Elements Reviewed

A revision of the programme allows a reduction of architectural components, which favours cost-cutting.

Identification of components that make up the functional and technical categories:

- External cladding or skins: façade, roofing

- Supporting plans: floor slabs

- Interior partitions: walls

- Fluid lines: pipelines (electrical, mechanical, gas, etc.)

A rational study of the design of the habitat facilitates its execution, towards economically optimised results, as many superfluous elements are eliminated.

Some components of functional space can be reduced: corridors and partitions for semi-private spaces, while compatible spaces can be unified.

On the other hand, the free plan, as Le Corbusier's paradigm, achieves the simplicity of relations between uses of the building, not conditioned by the rigid structural functions.

A well-coordinated structural choice can simplify internal partitioning conditions and eliminate redundant elements. (Figure 5).

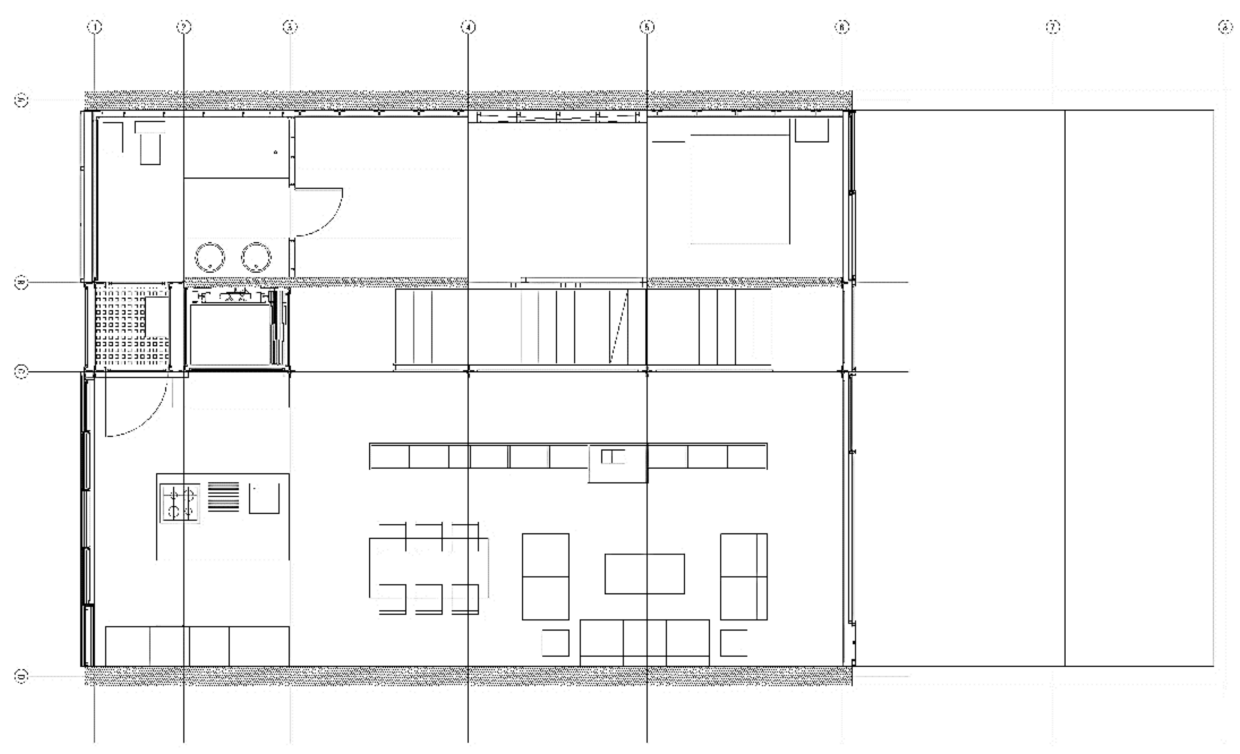

Figure 5. Housing plan: rehearsal of the organisation of a living space-J. Guardiola.

The application of the lean methodology in construction allows for the elimination of components that do not add value to the user, which is achieved by reviewing the needs of the habitat programme in the stages from the beginning of the project [31].

\subsection{Construction Engineering: Price Decomposition Analysis}

The analysis of productivity improvement in construction focuses on cost elements, not including other aspects such as management, organisation or quality.

The aim of systems engineering [32] is to formalise new ways of approaching the execution of the building, with which we will understand better the advantages of industrial approaches, using its own internal logic in the design.

However, it is not only necessary to industrialise the components for their industrial manufacture but also to go further, thinking about assembly and maintenance, summarized by contemplating the full $360^{\circ}$ cycle of the complete exploitation of the building asset.

Cost optimisation is studied based on the price decomposition of the construction components, following the elementary cost analytics known in construction. 
As far as execution concerns, including material and assembly, the material execution cost is established, which is broken down into three elementary prices:

- Price of materials.

- Manpower price.

- Price of auxiliary resources.

When analysing the construction timings for the execution process, different types of construction timings are found:

- Coordination times: one task depends on another to continue. Analysing the assembly, looking for solutions of "parallel" tasks and prioritising over "serial" tasks.

- Construction times of semi-finished components that are not finished for their function; looking for "finished" materials that do not require construction times.

- Weather: atmospheric conditions that condition construction (setting, drying); looking for processes and materials, independent of weather conditions.

The deadline is reduced, with the shortening of work times, in each of its modalities.

Therefore, the cost—-through its impact of manpower and auxiliary resources-the deadline and the design will be the scope dimensions of this study.

The Elements of the Material Execution Cost: Current Situation

Current construction uses old methods and materials, and the execution is highly conditioned by manpower and weather conditions and is very dependent on auxiliary resources.

The price of a construction element consists of: manpower, materials and auxiliary resources.

- Currently, in construction, the cost of the construction elements is involved in a differentiated manner, as explained below with the impact on the implemented component.

- Auxiliary resources: these are correlated by their time of use, which means that the shorter the time, the lower the cost.

- Materials: traditional, obsolete, archaic technology.

On the other hand, execution times are aggravated by current on-site construction methods, affected by weathering and by a linear sequence of jobs, which accumulate their times.

More extensively, these observations are further elaborated by differentiating for the three cost elements:

- Manpower considerations: Lack of homogeneity. No progress on the technical solution.

Construction work is affected by the weather. Improvisation, due to lack of detail in the design. Quantity over quality.

- Auxiliary resources represent two types of units:

Means charged directly on items, in which repercussion, according to companies, is in the range from 1 to $2 \%$ and refer to tools applied for internal finishing works, not applicable for installation works.

Special external means for lifting and external platforms and mixing and storing hydraulic materials, through which repercussion is a direct price and varies depending on the construction. These means are normally applied as a temporary rate, either as a rental or as amortisation, and are charged for the time employed, so that the term acts directly against these units.

- Material considerations:

Material adjustments to the geometry are necessary, resulting in waste: shrinkage and trimming.

Traditional materials without technological evolution, natural materials with few possibilities for development.

End caps, overlaps: special pieces to cover up or cover unavoidable defects.

Auxiliary resources required for their work: Moulds, formwork, scaffolding, platforms and cranes, etc. 
They require drying and setting times due to the use of hydraulic materials, usually binders and finishing materials.

- Timeframe considerations:

Semi-finished products, which require time for shaping, setting or drying.

Semi-finished products, which require a large amount of manpower to be produced on-site and therefore time consumed.

It is of interest to shift the manpower time from on-site to off-site production: workshop, factory or industrial factory.

Linear construction: chained times in traditional construction, with waiting times between them due to the difficulty of coordination between different trades.

\section{Results}

In summary, the following results can be deduced from the optimisation of the lean methodology in construction.

Firstly, in the same methodological order, through the results obtained from the analysis of the combination of technologies and products used in construction (Section 2.1.1), it can be determined that incoherent construction occurs when mixing craft technologies with factory-produced materials or industrial technologies using materials made on site.

According to the analysis of technologies and design (Section 2.1.2), there are four possibilities, distinguished between the design of the habitat and the construction technology provided.

- Rational and contemporary design combined with advanced technology: High tech.

- Conservative and outdated design and archaic construction: Traditional design.

- Rational design using a traditional construction technology.

- Conservative design using advanced technology.

- The first two possibilities are coherent and parallel between the design criteria and the technology chosen for their execution; however, the latter two produce an incoherent result.

From the stages of the project, studied in the methodology (Section 2.2), there are two areas in a construction project: The design and the execution.

Of the four design stages listed in the UNE-EN 15643-3-2012, conceptual design and preliminary design would be in the architecture project group, while technical design and detail design would be in the engineering execution group.

We summarize the review of the design definition of the programme (Section 2.3) followed by the results of the economic analysis of the price in construction. It is necessary to reduce architectural elements and resources, materials, and execution time.

\subsection{Reduction of Architectural Elements}

The results are obtained from the analysis of the construction systems and technologies used in relation to the design.

A rationalised design of the habitats' conditions, programme, space and uses, using arguments of the original design and fundamentally detached from traditional and conservative typologies can lead to innovative solutions along the lines of the savings sought in lean construction.

The rationalisation of construction is favoured on the defining elements of the architectural space, according to three differentiated modes:

- Elimination of corridors, lobbies, and room separations, resulting in consequent savings:

- Reduction of interior partitions

- Elimination of doors, passages between partitions.

- Compatibility of uses:

- Elimination of intermediate partitions

- Reducing the surface areas dedicated to service areas 
- Integration of:

- $\quad$ Structural elements in space divisions: load-bearing walls and bracing planes as implicit partitions.

- $\quad$ Furniture in compartmentalisation with cupboards, shelves, etc.

The rationalised design also facilitates the simplification of superfluous elements, simultaneously reducing costs and timescales.

- Elimination of decorative elements: Skirting boards, ceiling coving, etc.

- Reduction of the cladding of transit spaces: walls and ceilings.

- Elimination of installation aids.

- Elimination of cladding for structural elements (concrete, steel), leaving their exposed qualities.

Rational building design makes it possible to favour cost reduction by reducing the elements of architectural composition.

Rational architecture optimises spaces and construction elements.

These architectural conditions lead to saving in material resources, in the definition of habitat programs, in line with lean methodology.

Later, optimisation of construction can be completed, obtaining better production costs and further reductions in execution times.

As a specific result, applying what is analysed in the article and as an example that materialises industrialisation in housing in an experimental way, one of the authors brought together all the parameters analysed in his Guardiola-Babecka single-family house in Madrid, which has been awarded for its innovative proposal.

Figure 6 shows the interior environment of the house, in which elements of the space have been reduced to define different functions of the habitat.

\subsection{Cost Cutting: Resources, Materials and Execution Time}

From the construction price decomposition studied in Section 2.4, construction prices are composed of three components:

- Materials.

- Manpower.

- Auxiliary resources.

From these, the following options have been obtained within the framework of cutting and saving time and resources, along the lines of lean construction.

With industrial manufacturing, we reduce the impact of material costs; however, in order to reduce the manpower and auxiliary resources, it is necessary to think about the execution method, simplifying the deadlines.

As far as the construction method is concerned, a mechanised technical assembly allows not only less qualified manpower, with the consequent cost savings (the assemblers could be the users themselves, suitably directed and with assembly instructions), but also independence from climatic conditions, as no materials that have to set in dry weather, are involved.

The repercussion of manpower and auxiliary resources is directly related to the time used for assembly; if the period decreases, these cost components will decrease.

On the other hand, when comparing the prices of traditional materials with those of industrial origin, the price of industrial components shows a downward trend. 


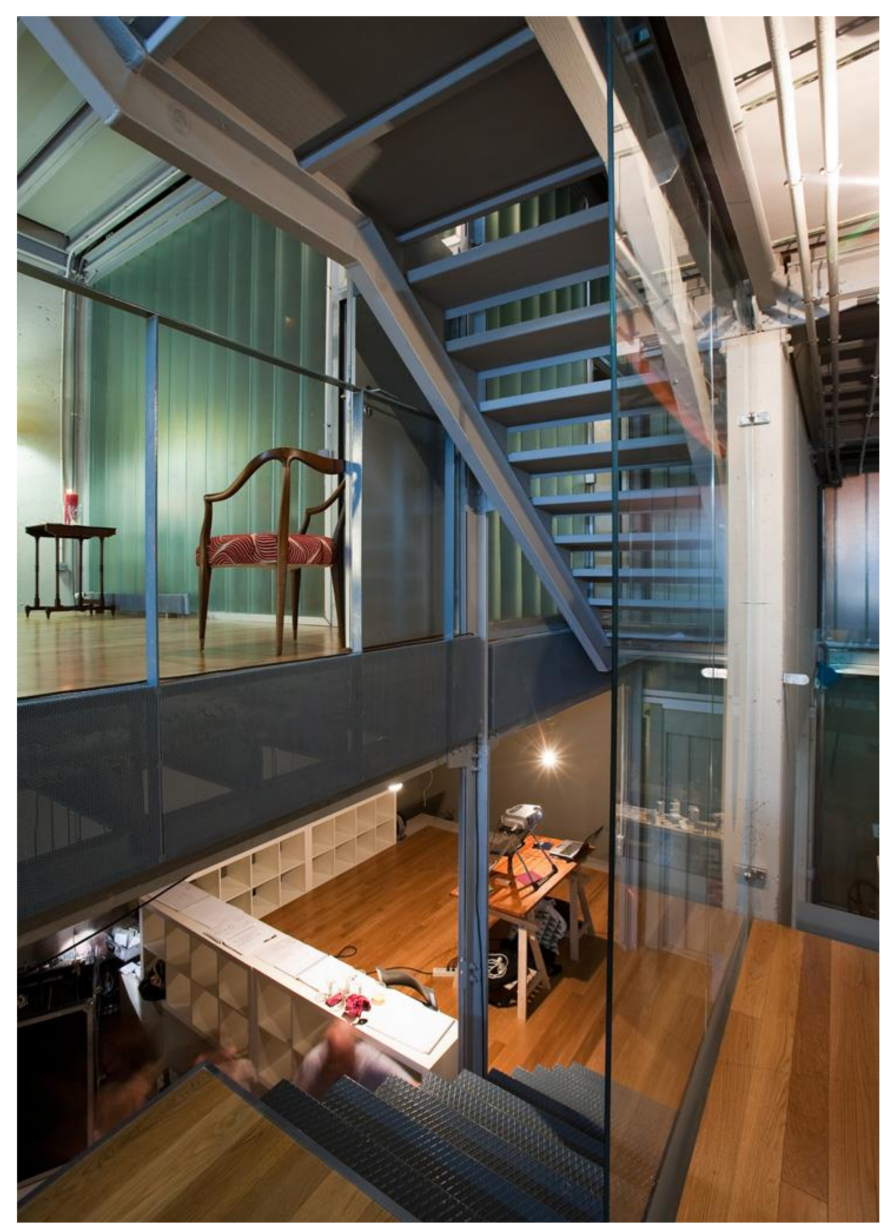

Figure 6. Interior of Guardiola-Babecka single-family house in Madrid.

They also serve to guide mechanised construction using the contents of "open industrialisation" applied to construction. In summary, the following arguments are the key to sustainable construction.

- Materials can also evolve in an increasingly cost-optimised way.

- Break the dependence of the material on manpower, reducing the impact of the former.

- Lower the impact of auxiliary resources.

- More optimised deadlines: overlapping tasks and obtaining shorter deadlines, delays due to waiting times between trades are reduced or eliminated altogether.

- Avoid drying and setting times for hydraulic materials.

\subsection{Streamlined Design: Transfer to Implementation (Productivity Improvement)}

A revised design over implementation, through industrialised construction, will improve the evaluation of the final cost.

Based on the above analysis, three strategies for change are observed, for the optimisation of the cost of implementation.

\subsubsection{Decrease the Impact of Manpower on the Materials}

The trend of the material cost for industrial products is downward, in contrast to the manpower, which is upward.

Consequently, a low manpower impact on the price of the material and a material of industrial origin with a negative trend: decreasing cost, generate a doubly decreasing total cost. (Figure 7). 


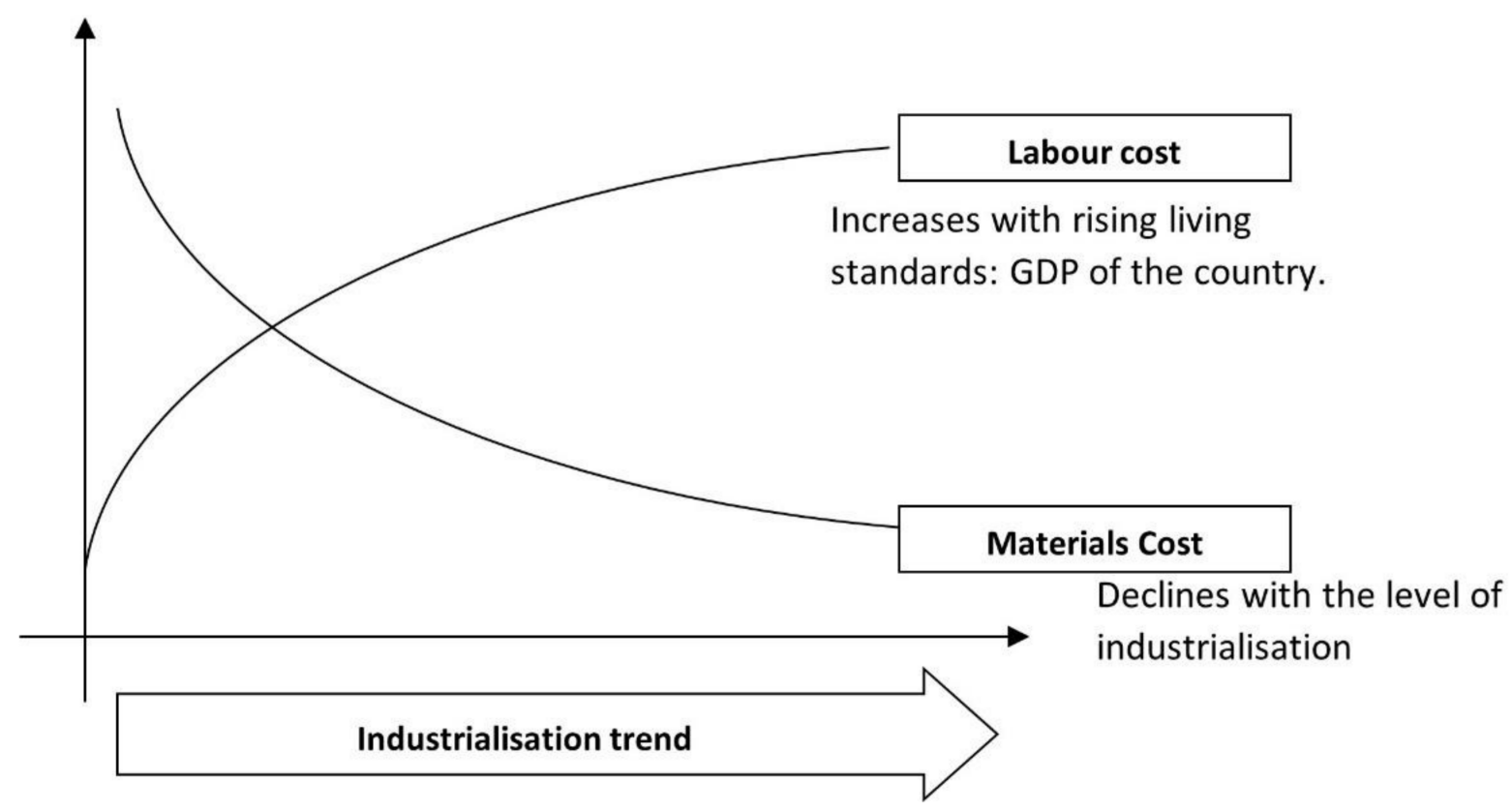

Figure 7. Industrialisation trend (own source).

Two aspects are therefore of interest:

- Materials can also evolve in a cost-optimised manner.

- Break the dependence of material on manpower by reducing the impact of the former.

\subsubsection{Lower Impact of Auxiliary Resources: Lower Indirect Costs}

Execution based on a design with a low impact of auxiliary resources generates a decreasing cost for two reasons: the elimination of auxiliary resources with a direct impact and the shorter time charged for those of external implementation.

\subsubsection{Shortening the Deadline by Shortened Times}

Time cuts should be sought in activities that overlap with finished products [33].

- More optimised lead times: with overlapping tasks and shorter lead times, delays due to waiting times between trades are reduced or eliminated altogether.

- Avoid drying and setting times of hydraulic materials.

- Performance improvement towards lean process technology in construction.

- Decrease the impact of manpower.

- Cost reductions due to elimination/cutting of indirect costs.

- Shortening the time limit for reduced times.

In summary, the improvement of performance towards a lean process technology in construction would be stated with the following arguments:

- Decrease the impact of manpower.

- Reduction of costs by eliminating indirect costs: auxiliary resources.

- Shortening of time due to reduced times.

Grouping into the three defined categories of the price under construction decomposition:

- Decrease the impact of manpower on materials.

- Lower repercussion of auxiliary resources: lower indirect cost.

- Shortening of the timeframe due to reduced times.

The prioritisation of material costs over manpower, by means of industrialised components specialised in their function and prepared for rapid assembly on site is characteristic of industrialised construction. 
Likewise, the reduction of lead times is an objective of the application of the tried and tested methods of industry in construction.

Both strategies, with the cost of resources and time, add up to the cuts that are characteristic of the application of lean construction.

As a summary of the results obtained in relation to the methodology used, the table in Figure 8 is shown.

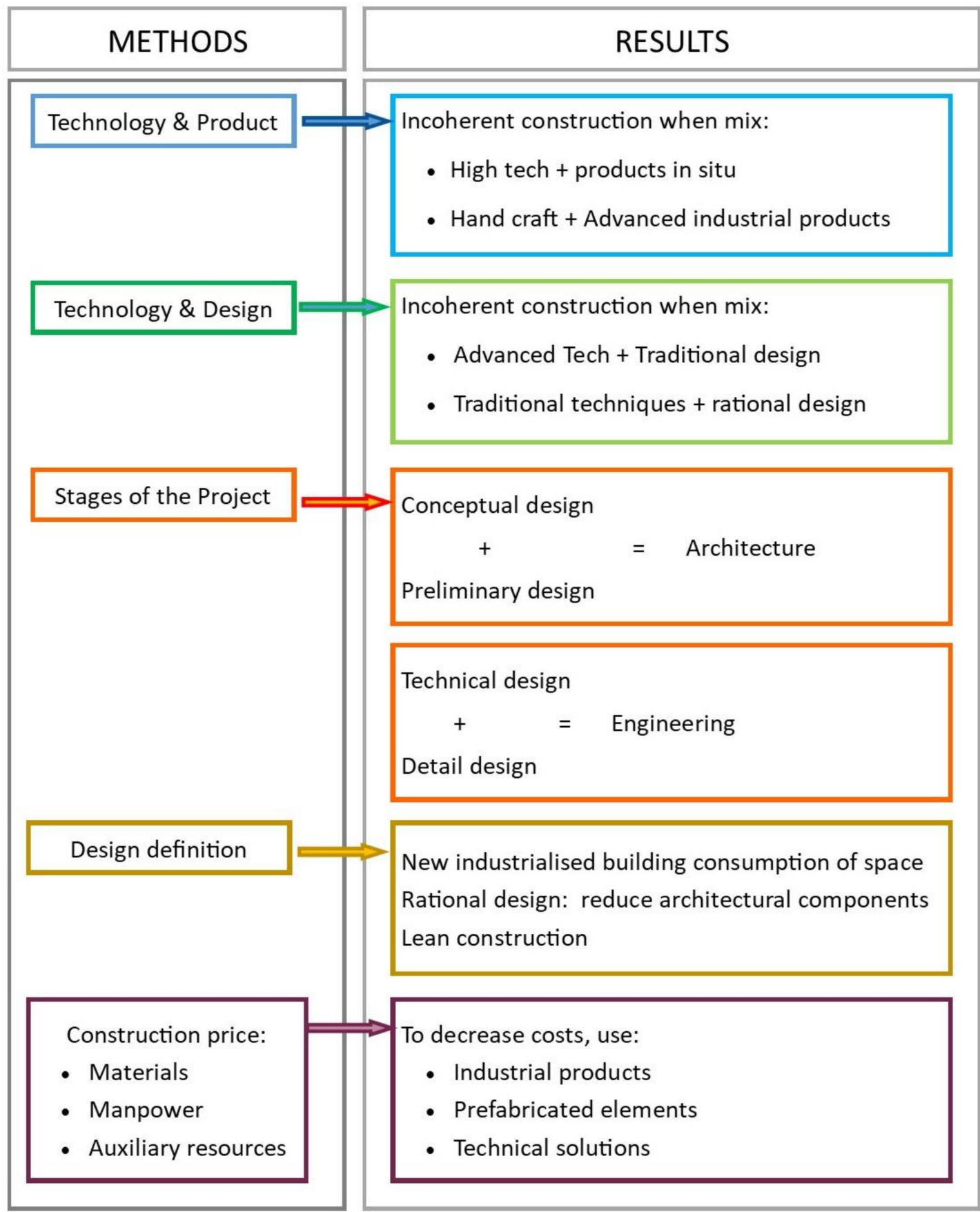

Figure 8. Methodology and results obtained (own source).

\section{Discussion}

\subsection{Coherent Building System}

Construction is improved with a complete and coherent building system that integrates: design, project and execution. 
As described at the beginning, through the analysis of construction design, integrating design and execution, opportunities have been found to improve productivity in building, justified in lean construction.

In small-scale projects, single-family or block dwellings, small office and commercial buildings, the only technician to develop the design is the architect, whose work usually ends with the basic level of the project, which is specified in the premises of the habitat, developed according to concepts of space organisation, and respecting the legal ordinances and regulations that affect it.

The detailed project for the execution remains in two contributions-the structure and the installations-without going deeper into the constructive analysis, which is taken for granted according to the traditional rules of construction.

In larger projects, the work is complemented by detailed engineering, developed by engineering specialists, outside the architect's organisation, with no other relationship than that of external professional collaboration, normally occasional and without continuity.

However, frequently, even in these cases, either the engineering does not understand the architect's design orientation, or the object of the architect's design is far removed from the parameters of the technical project.

In any case, the execution is not usually developed in-depth, analysing techniques, products and components, which rationalise the construction.

\subsection{Economic Parameters}

An analysis of the economic parameters was carried out where it was possible to identify cost and time reductions, based on the criteria of the construction itself, without including other disciplines:

- Break the dependence of the material on manpower, reducing the impact of the former.

- Reducing the effect of auxiliary resources.

- More optimized deadlines, overlapping tasks and obtaining shorter deadlines:

- Delays due to waiting times between trades, which are reduced or eliminated altogether.

- $\quad$ Avoid drying and setting times for hydraulic materials.

- Transferring time from site to "workshop".

New architectural optimization arguments have also been included to eliminate components of the habitat programme, which can be grouped into two categories:

1. Simplification of components:

- Habitat revision.

- Reduction of interior partitions.

- Elimination of doors, passages between compartments.

- Reducing dedicated surfaces in service areas: kitchens, offices.

- Structural in the divisions of space: load-bearing walls and bracing planes as implicit partitions.

These components define the functional programme of the habitat, which we have seen above, and are basic architectural elements at this level of design, principal elements, and involve both spatial and structural functions.

2. Simplification of superfluous elements:

- Furniture, in the compartmentalization with cupboards and shelving.

- Reduction of cladding and transit spaces: walls and ceilings and cladding: structural elements: concrete and steel, leaving their qualities visible.

- Exposed installations, elimination of installation aids: chases and skirting boards.

On the other hand, these components are of more secondary application for a design level of definition of shapes and textures, more definitions for style than as a functional program.

Performance improvement, towards a lean construction process technology, is summarized: 
1. Reductions of architectural elements, for a design, as a solution of the habitat program.

2. Optimization of costs and deadlines in execution:

- Decrease the impact of manpower on materials.

- Lower repercussion of auxiliary means: lower indirect cost.

- Shortening of time due to reduced times.

However, it would be necessary to quantify all these strategic lines, both those of an architectural nature and those of an economic nature, according to the cost and time of construction.

It would also be necessary to obtain a design basis combining the two strategies mentioned, a new method that would allow, in a systemic way, to align with these proposals and which justify a cost reduction on the final construction.

It is difficult to determine the reduction; it depends on the solution adopted, and it is not possible to give a general reduction parameter.

\subsection{C System: Compatible Components in Construction}

As a possible continuation of this article, we propose a design method that allows, within the discipline of design, to integrate the contemporary building into the current industrial environment.

This methodology is developed within systems engineering, adopting concepts and laws from its epistemological field.

Successful implementation of the lean concept as a sustainable approach in the construction industry depends on the identification of critical factors [34].

A system that focuses on industrialized components to obtain the two properties that we have obtained from the previous analysis. (Figure 9).

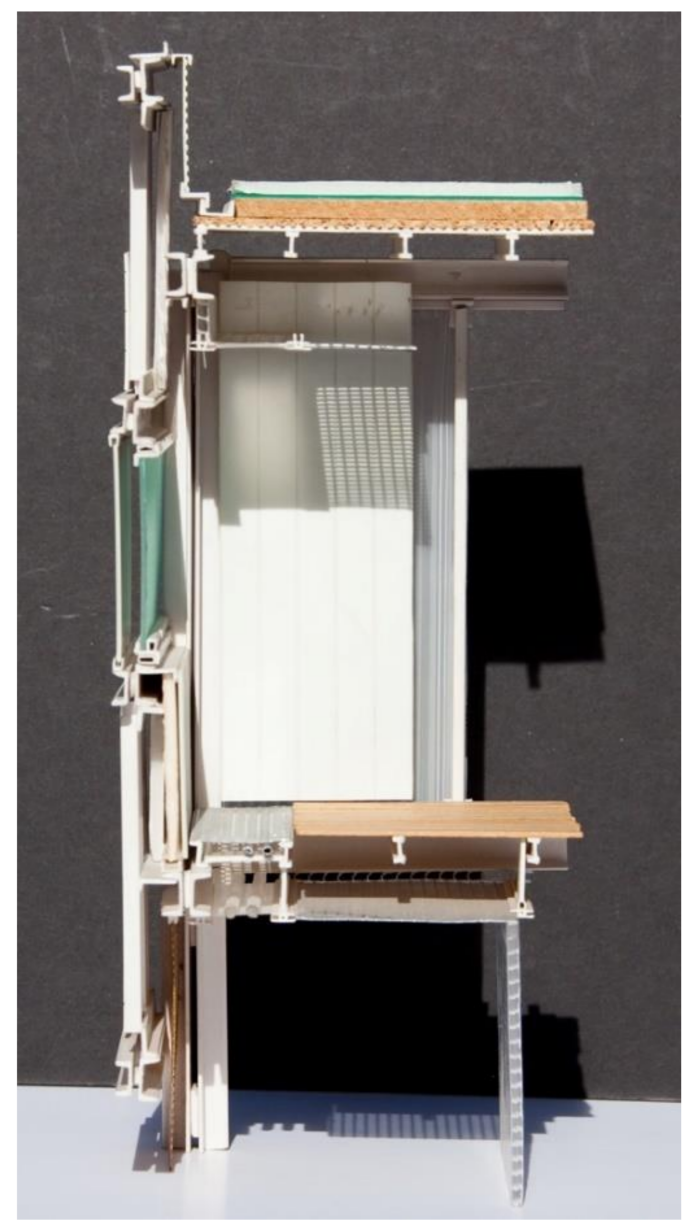

Figure 9. 3C system composition mock-up. J Guardiola A. 
To this end, we will seek application in the discipline of systems theory, specifically systems engineering, to find design arguments that achieve the objectives along the lines outlined above.

The model shows how strategic implementation facilitates the integration of lean construction and sustainable construction from the design phase to the finishing phase of a project [35].

A system that we call the $3 \mathrm{c}$ system: Compatible Components in Construction.

This proposal brings together these improvement objectives, using the criteria of sustainable construction through the so-called " $3 \mathrm{C}$ system: Compatible Construction Components". This system involves the use of prefabricated modules, factory materials and assembly using standardised joints. (Figure 10).

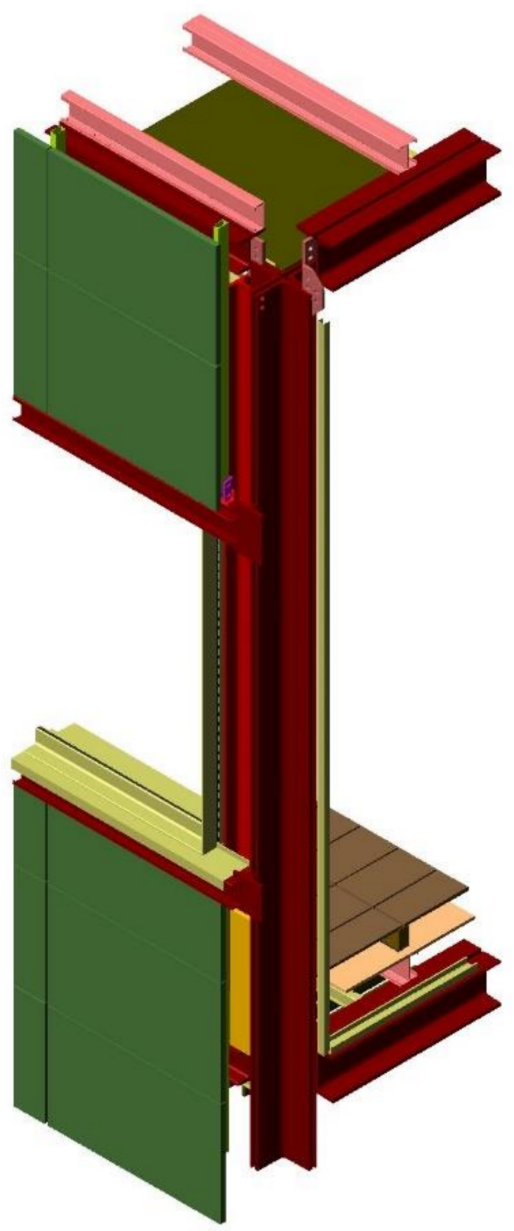

Figure 10. CAD model of the façade component of $3 \mathrm{C}$ system composition. J Guardiola A.

A design solution that will seek, first, to formalise its application principles, and then to contrast with traditional solutions, its optimisation operability, as a defined tool of lean construction [36]. (Figure 11).

\subsection{Lean Construction}

Finally, the lean construction methodology is confirmed as a tool that contributes to the sustainability of buildings [37] for the following reasons based on ISO 20887 [38]. This standard specifies aspects of sustainability in the field of recycling, dismantling and reuse in the field of construction. 


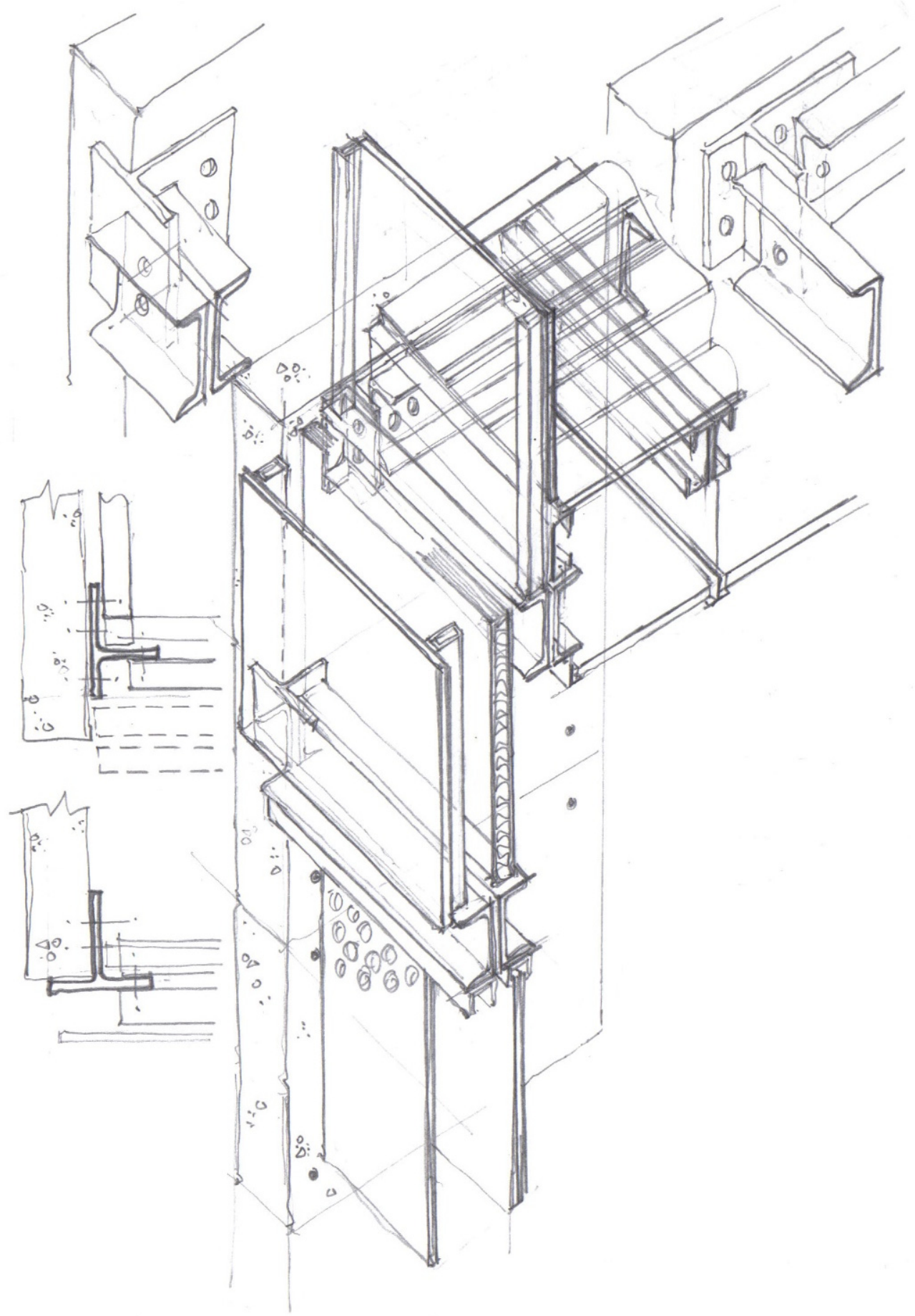

Figure 11. Drawing of the façade component of $3 \mathrm{C}$ system composition and connections to other components. J Guardiola A.

The following arguments stand out for the sustainability of the construction:

- For energy savings: on the construction site, the auxiliary resources are responsible for almost the entire energy consumption. This is discussed in the article with regard to the cost element, that of auxiliary resources.

- On materials, their manufacture (consumption), composition (non-polluting), recycling, proximity (transport savings, etc.) and specifically the focus on the "specialisation" of materials. This is also dealt with under the heading of "cost elements". 
- Cyclical economy: buildings, components and materials must be used for continuous reuse.

The first two are included in the analysis of cost elements, carried out previously, the third one is considered below, using the above-mentioned ISO 20887 standard as a reference.

This standard, ISO 20887: Design for disassembly and adaptability of buildings and civil engineering works, is structured on specific contents that determine design aspects to be applied to construction assets, of which we highlight the following.

Lean practices show the reduction of environmental, economic, and social impacts during the construction phase, and increase sustainability parameters in the development of projects [39].

Standardisation (seiketsu standardize) facilitates transport, storage, and reuse. It makes it possible to include the aspects of adaptability and simplicity.

Standardisation avoids waste, adapts to logistical, ergonomic, and functional requirements.

The constructive design is favoured by standardisation aspects such as: components, dimensions, and modules.

Simplicity, as a design principle, reduces the number of elements, components and materials to the minimum required to perform the intended function.

This includes limiting the use of decorative details, minimising the number and diversity of materials.

One of the objectives is the elimination of waste in disassembly, aided by the simplification of tools and techniques required for disassembly. This directly improves the appearance of cleanliness (seiso shine), eliminating debris and debris and keeping the workspace tidy.

Lean methodology seeks the reduction of "waste". This "waste" can also be assumed in construction in different categories [40]:

1. Defects

2. Overproduction

3. Waiting

4. Non-utilized skills/capabilities

5. Transportation

6. Inventory

7. Motion

8. Over-processing

By increasing the functions that material provides, it contributes to dematerialisation in construction, thus reducing the problem of material layering.

Order and systematisation in construction is a fundamental aspect of the work. Seiton, set in order, organises, and places the necessary materials according to the order of use by zones on the construction site and establishes the areas where these stockpiles, auxiliary resources, reusable material, and rubble, etc. are to be made.

Independence is particularly important for the "levels" of the construction, related to the temporal prediction of the function of each component.

The main levels that can be identified are:

- Shell or carcass: structure, foundations, and envelopes.

- Services: installations, ducts, pipelines, and machinery.

- Finishes: flooring, ceilings, walls, and panelling.

- Equipment: furniture and lamps.

The challenge is to achieve independence without compromising the functionality of systems and materials in their integration.

Independence facilitates the separation and disconnection of building systems, favouring spatial and functional adaptation and the reuse of systems. In addition, disassembly shall allow materials and components to be removed without disrupting other components or materials. 
The levels of a building shall be differentiated to facilitate adaptation and dismantling. Separating levels of long-life components from those of shorter life facilitates retrofitting and reduces the complexity of dismantling.

Durability is defined for an asset or component as the ability to perform as required for its specified period of time without the need for repair or modification.

Durability and adaptability are close concepts.

To minimise maintenance or repair, materials with a long service life should be used. In other cases, shorter life designs are required, with easy disassembly and consequent re-use of components and materials.

The accessibility of components, especially connecting elements with a shorter service life, facilitates replacement and avoids damage to adjacent elements of the assembly. Another advantage is that disassembly of these components from the building sometimes does not require special equipment.

The requirement for easy access to connectors can have an aesthetic impact on the building design.

The discipline of improvement is necessary; shitsuke sustain propose maintenance, sustaining process to create the habit, explaining to the team how it works and how it is maintained.

An open construction, where parts are interchangeable, allows for modifications in the implementation without significant repercussions.

All in all, these reasons contribute to the fact that "Lean Construction not only contributes to creating the economic value to the construction process but can also contribute to promoting the environmental and social issues" [41] and meets several points of the objectives for sustainable development (OSD):

With the development of new building techniques [10], lower consumption of material and energy resources and the planning of the building life cycle, more sustainable cities and population centres can be achieved [12].

Controlling resources and reducing waste through Lean techniques will lead to responsible production and consumption [13].

\section{Conclusions}

In order to improve productivity, in the current situation of construction, the transfer to industrialisation is essential.

With a complete building system, integrated by design, project and execution, the construction is improved and more sustainable.

It can be determined that incoherent construction occurs when mixing craft technologies with factory-produced materials or industrial technologies using materials made on site. (Figure 1).

Incoherent construction is also made when advanced technologies are used with a traditional design or when traditional techniques are combined with a rational design. (Figure 2).

A lean analysis in construction must be based on the order of stages established in construction projects, as set out in the UNE-EN 15643-3-2012. Of the four design stages, conceptual design and preliminary design would be in the project architecture group, while technical design and detail design would be in the execution engineering group.

The habitat system must correspond to new modes of construction, which respect the arguments obtained by the new type of buildings.

Reducing the cost of construction is of great importance, both from an economic and a social point of view.

Attempts to reduce the cost of traditional manual labour methods by introducing more rigorous organisational techniques have so far produced only a little progress.

On the other hand, numerous studies, both technical and sociological, have reviewed the human habitat, looking for more rational solutions, which have an impact on space-saving. 
The repercussion of manpower and auxiliary resources is directly related to the time used for assembly; if the period of time decreases, these cost components will decrease.

The new objective, uniting both trends, is to seek construction by means of industrial production methods with spaces that meet the real needs of the habitat.

Industrial production must necessarily go through a manufacturing process at the ground level, using components that can be assembled "in situ". Modern technology is already prepared to take this step, but today's construction still uses archaic manual methods, in which the machine plays only an auxiliary role.

From the project phases of architectural design, reviewing the habitat and the defining components of the spaces to the execution phases of engineering and analysing process improvements from the analytical decomposition of the prices of building components, opportunities have been found to improve the construction process.

A new methodology should bring together these improvement objectives, using the criteria of construction sustainability, through the so-called " $3 \mathrm{C}$ system: Compatible Building Components". This system involves the use of prefabricated modules, factory materials and assembly by means of standardised joints.

The application of the BIM methodology in the building's life cycle can go from the beginning of the design to its demolition. This building life can be programmed efficiently, if, during the design process and its execution, the lean methodology is applied, seeking to reduce waste, saving time and materials.

As a final conclusion, it is established that the elements that must integrate a complete and coherent building project require the incorporation of industrial manufacturing and lean methodology in the construction processes in order to achieve sustainable architecture.

Author Contributions: Conceptualization, T.A. and J.G.; methodology, T.A. and J.G.; software, D.F.; validation, T.A. and D.F.; formal analysis, T.A. and J.G.; investigation, T.A. and J.G.; resources, J.G.; data curation, T.A. and D.F.; writing-original draft preparation, J.G. and T.A.; writing-review and editing, T.A.; visualization, T.A. and D.F.; supervision, J.G. and D.F.; project administration, T.A. and D.F.; funding acquisition, T.A., J.G. and D.F. All authors have read and agreed to the published version of the manuscript.

Funding: This research received no external funding.

Institutional Review Board Statement: Not applicable.

Informed Consent Statement: Not applicable.

Acknowledgments: Thanks to all the organizations and people who participated in the project, particularly to professors who have a spirit of continuous improvement.

Conflicts of Interest: The authors declare no conflict of interest. The funders had no role in the design of the study; in the collection, analyses, or interpretation of data; in the writing of the manuscript, or in the decision to publish the results.

\section{References}

1. Resta, B.; Dotti, S.; Gaiardelli, P.; Boffelli, A. Lean Manufacturing and Sustainability: An Integrated View. In Proceedings of the IFIP International Conference on Advances in Production Management Systems, Iguassu Falls, Brazil, 3-7 September 2016; Springer: Berlin/Heidelberg, Germany, 2016; pp. 659-666.

2. Gao, S.; Low, S.P. The Toyota Way. In Lean Construction Management: The Toyota Way; Gao, S., Low, S.P., Eds.; Springer: Singapore, 2014; pp. 49-100, ISBN 978-981-287-014-8.

3. Marhani, M.A.; Jaapar, A.; Bari, N.A.A. Lean Construction: Towards Enhancing Sustainable Construction in Malaysia. ProcediaSoc. Behav. Sci. 2012, 68, 87-98. [CrossRef]

4. Abdelhamid, T. Lean construction: Where are we and how to proceed. Lean Constr. 2004, 1, 24.

5. Sandvik, C.; Fougner, F. BIM as a Tool for Sustainable Design. Proceedings of 5th fib Congress, Melbourne, Australia, 8 October 2018.

6. United Nations. Transforming Our World: The 2030 Agenda for Sustainable Development; A/RES/70/1; UN: New York, NY, USA, 2015.

7. Bae, J.-W.; Kim, Y.-W. Sustainable Value on Construction Projects and Lean Construction. J. Green Build. $2008,3,156-167$. [CrossRef] 
8. Goñi, P.M.; Barroso, J.M.G.; Rey, A.R.E. The "Design for Disassembly", a Lean Methodology. In Proceedings of the 5th European Conference on Energy Efficiency and Sustainability in Architecture and Planning, San Sebastian, Spain, 7-9 July 2014. [CrossRef]

9. Saieg, P.; Sotelino, E.D.; Nascimento, D.; Caiado, R.G.G. Interactions of Building Information Modeling, Lean and Sustainability on the Architectural, Engineering and Construction Industry: A Systematic Review. J. Clean. Prod. 2018, 174, 788-806. [CrossRef]

10. Tzortzopoulos, P.; Kagioglou, M.; Koskela, L. Lean Construction: Core Concepts and New Frontiers; Routledge: London, UK, 2020; ISBN 978-0-429-51215-5.

11. Solaimani, S.; Sedighi, M. Toward a Holistic View on Lean Sustainable Construction: A Literature Review. J. Clean. Prod. 2020, 248, 119213. [CrossRef]

12. Brookfield, E.; Emmitt, S.; Hill, R.; Scaysbrook, S. The Architectural Technologist's Role in Linking Lean Design with Lean Construction. In Proceedings of the 12th Annual Conference of the International Group for Lean Construction, Helsingør, Denmark, 3-5 August 2004; p. 7.

13. Mathaisel, D.F.X. A Lean Architecture for Transforming the Aerospace Maintenance, Repair and Overhaul (MRO) Enterprise. Int. J. Product. Perform. Manag. 2005, 54, 623-644. [CrossRef]

14. Ogunbiyi, O.; Goulding, J.S.; Oladapo, A. An Empirical Study of the Impact of Lean Construction Techniques on Sustainable Construction in the UK. Constr. Innov. 2014, 14, 88-107. [CrossRef]

15. Emuze, F.A.; Saurin, T.A. Value and Waste in Lean Construction; Routledge: London, UK, 2015; ISBN 978-1-317-44763-4.

16. Koskela, L. Application of the New Production Philosophy to Construction; CIFE Technical Report; Stanford University: Stanford, CA, USA, 1992; Volume 72.

17. Rajadell, M.; Sánchez, J. Lean Manufacturing: La Evidencia de Una Necesidad; Díaz de Santos: Madrid, Spain, 2010.

18. Corbusier, L.; Eardley, A. The Athens Charter; Grossman Publishers: New York, NY, USA, 1973; ISBN 0-670-13970-X.

19. Fieber, K.; Mills, J.; Peppa, M.V.; Haynes, I.; Turner, S.; Turner, A.; Douglas, M.; Bryan, P. Cultural heritage through time: A case study at Hadrian's wall, United Kingdom. ISPRS—Int. Arch. Photogramm. Remote Sens. Spat. Inf. Sci. 2017, 42, 297-302. [CrossRef]

20. Koolhaas, R.; Obrist, H.U. Project Japan, Metabolism Talks; Taschen: Cologne, Germany, 2011; ISBN 978-3-8365-2508-42019.

21. Sadler, S. Archigram: Architecture without Architecture; Mit Press: Cambridge, MA, USA, 2005; ISBN 0-262-69322-4.

22. Garnier, T. An Industrial City; Princeton Architectural Press: New York, NY, USA, 1989; ISBN 0-910413-47-9.

23. Oechslin, W.; Wang, W. Les Cinq Points d'une Architecture Nouvelle. Assemblage 1987, 4, 83-93. [CrossRef]

24. Fernández, J.R. La Arquitectura Prefabricada de Rafael de la Hoz en Córdoba: Entre el Detalle Constructivo y la Generación del Proyecto. Universidad de Sevilla, 2016. Available online: https: / / dialnet.unirioja.es/servlet/tesis?codigo=47825 (accessed on 22 October 2021).

25. Radić, J.; Kindij, A.; Mandić Ivanković, A. History of Concrete Application in Development of Concrete and Hybrid Arch Bridges; Chinese-Croatian Joint Colloquium Long Arch Bridges: Brijuni Island, Croatia, 10-14 July 2008; p. 24.

26. Stanford University and the 1906 Earthquake. Available online: https:/ /quake06.stanford.edu/centennial/gallery/structures/ museum/index.html (accessed on 22 October 2021).

27. Association pour la mémoire et le rayonnement des travaux d'Eugène Freyssinet (Ed.) Eugène Freyssinet: A Revolution in the Art of Construction; Presses de l'école nationale des ponts et chaussées: Paris, France, 2004; ISBN 978-2-85978-394-5.

28. Smith, R.E. Prefab Architecture: A Guide to Modular Design and Construction; John Wiley \& Sons: Hoboken, NJ, USA, 2010; ISBN 978-0-470-27561-0.

29. Moles, A.A. Rohmer, Elisabeth Sicología del Espacio; Editorial Ricardo Aguilera: Madrid, Spain, 1972; ISBN 978-84-7005-114-2.

30. Fernández Alba, A. La Crisis de la Arquitectura Española (1939-1972); E.T.S. Arquitectura (UPM): Madrid, Spain, 1972.

31. Díaz, H.P.; Rivera, O.G.S.; Guerra, J.A.G. Filosofía Lean Construction para la gestión de proyectos de construcción. Avances Investigacion en Ingeniería 2014, 11, 32-53. [CrossRef]

32. Kwofie, S.; Pasquire, C. Lean Thinking for Structural Engineers. In Proceedings of the 28th Annual Conference of the International Group for Lean Construction (IGLC), Berkeley, CA, USA, 6-10 July 2020.

33. Aslam, M.; Gao, Z.; Smith, G. Exploring Factors for Implementing Lean Construction for Rapid Initial Successes in Construction. J. Clean. Prod. 2020, 277, 123295. [CrossRef]

34. Dehdasht, G.; Ferwati, M.S.; Zin, R.M.; Abidin, N.Z. A Hybrid Approach Using Entropy and TOPSIS to Select Key Drivers for a Successful and Sustainable Lean Construction Implementation. PLoS ONE 2020, 15, e0228746. [CrossRef] [PubMed]

35. Jamil, A.H.A.; Fathi, M.S. The Integration of Lean Construction and Sustainable Construction: A Stakeholder Perspective in Analyzing Sustainable Lean Construction Strategies in Malaysia. Procedia Comput. Sci. 2016, 100, 634-643. [CrossRef]

36. Carvalho, B.S.D.; Scheer, S. Lean as an Integrator of Modular Construction. Modul. Offsite Constr. (MOC) Summit Proc. 2019, 149-156. [CrossRef]

37. Ogunbiyi, O.E. Implementation of the Lean Approach in Sustainable Construction: A Conceptual Framework. Ph.D. Thesis, University of Central Lancashire, Lancashire, UK, 2014.

38. ISO Comitee ISO 20887:2020 Sustainability in Buildings and Civil Engineering Works—Design for Disassembly and AdaptabilityPrinciples, Requirements and Guidance. Available online: https:/ /www.iso.org/cms/render/live/en/sites/isoorg/contents/ data/standard/06/93/69370.html (accessed on 22 October 2021).

39. Carvajal-Arango, D.; Bahamón-Jaramillo, S.; Aristizábal-Monsalve, P.; Vásquez-Hernández, A.; Botero, L.F.B. Relationships between Lean and Sustainable Construction: Positive Impacts of Lean Practices over Sustainability during Construction Phase. J. Clean. Prod. 2019, 234, 1322-1337. [CrossRef] 
40. Tafazzoli, M.; Mousavi, E.; Kermanshachi, S. Opportunities and Challenges of Green-Lean: An Integrated System for Sustainable Construction. Sustainability 2020, 12, 4460. [CrossRef]

41. Bajjou, M.S.; Chafi, A.; Ennadi, A.; El Hammoumi, M. The Practical Relationships between Lean Construction Tools and Sustainable Development: A Literature Review. J. Eng. Sci. Technol. Rev. 2017, 10, 170-177. [CrossRef] 